\title{
Metabolic responses to water deficit in two Eucalyptus globulus clones with contrasting drought sensitivity
}

\author{
A. L. SHVALEVA, ${ }^{1-3}$ F. COSTA E. SILVA, ${ }^{1}$ E. BREIA, ${ }^{1}$ L. JOUVE, ${ }^{4}$ J. F. HAUSMAN,${ }^{4}$ \\ M. H. ALMEIDA, ${ }^{1}$ J. P. MAROCO,${ }^{5}$ M. L. RODRIGUES, ${ }^{1}$ J. S. PEREIRA ${ }^{1}$ and M. M. CHAVES ${ }^{1,2}$ \\ ${ }^{1}$ Instituto Superior de Agronomia, Tapada da Ajuda, 1349-017 Lisboa, Portugal \\ ${ }^{2}$ Laboratório de Ecofisiologia Molecular, IBET-ITQB, Apt.12, Oeiras 2784-505, Portugal \\ 3 Corresponding author (shvaleva@itqb.unl.pt) \\ ${ }^{4}$ Centre de Recherche Public Gabriel Lippmann, Cellule de Recherche en Environnement et Biotechnologies 162A, Av. de la Faïencerie, L-1511, \\ Luxembourg \\ 5 Instituto Superior de Psicologia Aplicada, Rua Jardim do Tabaco, 44 1149-041 Lisboa, Portugal
}

Received June 8, 2004; accepted May 28, 2005; published online November 8, 2005

\begin{abstract}
Summary We compared the metabolic responses of leaves and roots of two Eucalyptus globulus Labill. clones differing in drought sensitivity to a slowly imposed water deficit. Responses measured included changes in concentrations of soluble and insoluble sugars, proline, total protein and several antioxidant enzymes. In addition to the general decrease in growth caused by water deficit, we observed a decrease in osmotic potential when drought stress became severe. In both clones, the decrease was greater in roots than in leaves, consistent with the observed increases in concentrations of soluble sugars and proline in these organs. In roots of both clones, glutathione reductase activity increased significantly in response to water deficit, suggesting that this enzyme plays a protective role in roots during drought stress by catalyzing the catabolism of reactive oxygen species. Clone CN5 has stress avoidance mechanisms that account for its lower sensitivity to drought compared with Clone ST51.
\end{abstract}

Keywords: antioxidant enzymes, osmotic potential, proline, sugars, water stress.

\section{Introduction}

Soil and atmospheric water deficits are among the most important factors limiting plant growth and photosynthesis. Both kinds occur during Mediterranean summers, together with high temperatures and high irradiances. Eucalyptus globulus Labill., an economically valuable species in Portugal, is an evergreen tree that can survive all but extreme Mediterranean summer conditions. It grows best along the Atlantic coast where the Mediterranean climate is tempered by oceanic influence (Pereira and Chaves 1993).

To cope with periods of drought, plants rely on various drought-avoidance and drought-tolerance mechanisms that vary with genotype (Chaves et al. 2002). Adaptive mechanisms enabling plants to withstand abiotic environmental stress include changes in morphological, physiological and biochemical characteristics such as: (1) root system depth (Volaire et al. 1998); (2) control over leaf transpiration rates (Maroco et al. 1997) or transpirational surface, either through leaf abscission or growth inhibition (Chaves et al. 2003, Munné-Bosch and Alegre 2004); (3) osmoprotectant pool size (Delauney and Verma 1993); and (4) tissue dehydration tolerance (Volaire et al. 1998). At the cellular level, drought can affect the production of reactive oxygen species (ROS) (Smirnoff 1998) that may play a role in intracellular signaling (Finkel 1998) beside causing oxidative stress, which can be diagnosed by the accumulation of lipid peroxides, oxidized proteins and modified DNA bases (Rubio et al. 2002). Detoxification of ROS is dependent on a system of antioxidant enzymes and metabolites (Polle and Rennenberg 1992). Enzymes such as glutathione reductase (GR), ascorbate peroxidase (APX), superoxide dismutase (SOD) and catalase (CAT) play a key role in the scavenging of ROS such as superoxide $\left(\mathrm{O}_{2}^{-}\right)$, hydrogen peroxide $\left(\mathrm{H}_{2} \mathrm{O}_{2}\right)$, hydroxyl $(\mathrm{OH})$ and singlet oxygen $\left({ }^{1} \mathrm{O}_{2}\right)$, which are the initiators of a reaction chain leading to the degradation of cellular components (Sgherri et al. 2000). Under optimal growth conditions, antioxidant enzymes and metabolites from leaves detoxify ROS, thus minimizing oxidative damage (Smirnoff 1998). During periods of environmental stress, e.g., periods of drought or high irradiance, additional protective processes involving $\beta$-carotene, zeaxanthin and antheraxanthin synthesis participate in the deactivation of ROS (Garcia-Plazaola et al. 1997, Medrano et al. 2002).

Although the antioxidant defenses of trees have been studied in relation to environmental stresses such as high altitude (Polle and Rennenberg 1992), pollution (Wingsle and Hallgren 1993) and low temperature (Nakagara and Sagisaka 1984), few studies have focused on the activity of such systems in response to water deficits, and rarely in water- stressed Eucalyptus plants (Osawa and Namiki 1985, Osawa et al. 1992). Because some regions in which E. globulus is grown 
commercially, e.g., southern Portugal, experience hot, dry summers, knowledge of the role of antioxidants as a protective system may be useful in tree breeding programs.

During dehydration, osmolytes (mainly proline, glycine betaine and sugars) can help preserve protein and membrane structure and function (Smirnoff 1998). Although changes in soluble and insoluble sugar concentrations in leaves of water-stressed E. globulus have been studied (Quick et al. 1992), little is known about the changes in osmotically active compounds in roots of water-stressed E. globulus.

Fast growing Eucalyptus species are likely to be severely affected by drought. Costa e Silva et al. (2004) studied two E. globulus clones differing in drought sensitivity in the field (Clone ST51 is more drought sensitive than Clone CN5) and found clonal differences in the type and magnitude of response to water stress. The better performance of Clone CN5 under drought conditions was associated with faster root growth and higher stem hydraulic conductance compared with Clone ST51.

In recent years, new E. globulus plantations have used clones selected for high pulp yield. In Portugal, it is desirable that selected clones are well adapted to the Mediterranean summer drought. The present study was undertaken to determine if the leaves and roots of E. globulus Clones ST51 and CN5 exhibit metabolic differences when subjected to a gradually imposed water deficit. Metabolic responses to water deficit were investigated by measuring leaf pigment composition as well as osmotic potential, osmotically active compounds (proline, sugars) and enzymes with antioxidant activity in leaves and roots.

\section{Materials and methods}

\section{Plant material}

Rooted cuttings of E. globulus Clones ST51 and CN5, grown in plastic containers filled with a 3:2 (v/v) peat:styrofoam mix, were obtained from Aliança Florestal, Portugal, and transplanted after 11 months of growth in a nursery to 10-1 plastic pots filled with a fine sandy soil. One month after transplanting, each pot was enclosed in a dark plastic bag tied to the stem to prevent soil evaporation. The potted cuttings were placed in a greenhouse in a day/night temperature of $22 / 16^{\circ} \mathrm{C}$ and a relative humidity of about $60 \%$. The mean reduction in solar irradiance in relation to outdoor conditions on a sunny day was about 25\% (Faria et al. 1996). On September 9, 2002, 16 cuttings per clone were assigned to a well-watered regime with watering equal to transpiration loss. The remaining 16 cuttings per clone were assigned to a water-stress regime with watering equal to $50 \%$ of transpiration loss. The amount of water supplied was calculated from the difference in pot weight between successive watering. All plants were watered to the point of runoff on the first day and then watered twice per week (Monday and Friday) according to treatment regime. The treatments continued for 7 weeks (September 9 to October 29, 2002).

\section{Plant water status}

Predawn $\left(\Psi_{\mathrm{pd}}\right)$ and midday $\left(\Psi_{\mathrm{md}}\right)$ leaf water potential were measured daily at 0500 and $1300 \mathrm{~h}$, respectively, with a Scholander-type pressure chamber (PMS Instruments, Corvallis, OR) in six plants per treatment $(n=6)$.

Measurements of osmotic potential $\left(\Psi_{\pi}\right)$ were made on previously frozen 6-mm diameter leaf discs and root segments by thermocouple psychrometry, using C-52 sample chambers connected to a Wescor HR-33T dew-point microvoltmeter (Wescor, Logan, UT). The chambers were calibrated with standard $\mathrm{NaCl}$ solutions. After thawing, and following a 2-h equilibration period, osmotic potentials of the samples were measured by the dew-point method. Room temperature during the measurements was $20 \pm 1^{\circ} \mathrm{C}$.

\section{Sampling}

At the end of the 7-week treatment, 6-mm diameter leaf discs were collected from fully expanded leaves $(0.5 \mathrm{~g}$ fresh mass) at predawn and root segments were excised from the central part of the root system $(0.5 \mathrm{~g}$ fresh mass and diameter $<2 \mathrm{~mm})$. Samples were collected from five plants per treatment, frozen immediately in liquid nitrogen and stored at $-80{ }^{\circ} \mathrm{C}$ until analyzed.

\section{Growth analysis}

At the end of the 7-week treatment, the plants were harvested and shoots were separated into stem, lateral branches and stem leaves. Roots were gently washed and carefully separated from soil and other debris. Plant components were dried for at least $48 \mathrm{~h}$ at $80{ }^{\circ} \mathrm{C}$ in the oven and cooled in desiccators for dry mass determination. Leaves and roots were scanned before drying and leaf area and root parameters (length, diameter, area) of each seedling (five plants per treatment) were calculated with Delta-T scan software (Delta-T Devices, Cambridge, U.K.). Roots were assumed to be cylindrical and root surface area was calculated by multiplying the projected area by $\pi$.

\section{Soluble and insoluble sugars}

Soluble and insoluble sugars in leaves and roots were assayed by the anthrone method (Robyt and White 1987). Frozen leaf discs $(0.02 \mathrm{~g})$ and root segments $(0.05 \mathrm{~g})$ were ground with a cold mortar and pestle in liquid $\mathrm{N}_{2}$ with $1 \mathrm{ml}$ of $70 \%(\mathrm{v} / \mathrm{v})$ ethanol. The homogenate was thermomixed twice at $60{ }^{\circ} \mathrm{C}$ for $30 \mathrm{~min}$, centrifuged at $14,000 \mathrm{~g}$ for $5 \mathrm{~min}$ and the supernatant used for determination of soluble sugars. To extract insoluble sugars from the pellet, $1 \mathrm{ml}$ of acetone was added, the mixture was centrifuged at 14,000 $\mathrm{g}$ for $5 \mathrm{~min}$ and the supernatant discarded. One $\mathrm{ml}$ of $\mathrm{HCl}(1.1 \%)$ was added to the dry pellet, which was thermomixed twice at $60{ }^{\circ} \mathrm{C}$ for $30 \mathrm{~min}$ and centrifuged at 14,000 $\mathrm{g}$ for $5 \mathrm{~min}$. Absorbance of the insoluble sugars in the supernatant was determined at $620 \mathrm{~nm}$ with a spectrophotometer (U-2001; Hitachi, Japan). A calibration curve was prepared with standard glucose solutions.

The contribution of sugars and proline to osmotic potential was calculated according to the Van't Hoff equation: 


$$
\Psi_{\pi}=-c R T
$$

where $c$ is molal concentration of soluble sugars or proline, $R$ is the gas constant and $T$ is absolute temperature. Estimates of the contribution of these solutes to osmotic potential were based on the water content of the samples.

\section{Proline and leaf pigments}

About $100 \mathrm{mg}$ of fresh plant material was homogenized in $1.5 \mathrm{ml}$ of $3 \%$ thiobarbituric acid, shaken vigorously for $1 \mathrm{~min}$ and centrifuged at $15,000 \mathrm{~g}$ for $10 \mathrm{~min}$ at $4{ }^{\circ} \mathrm{C}$. The supernatant was assayed for proline, as described by Bates et al. (1973), by incubating $0.5 \mathrm{ml}$ of extract with $1 \mathrm{ml}$ of ninhydrin acid and $1 \mathrm{ml}$ of glacial acetic acid for $1 \mathrm{~h}$ at $100{ }^{\circ} \mathrm{C}$. The reaction mixture was rapidly cooled in ice and $1 \mathrm{ml}$ of toluene added and mixed vigorously. Absorbance of the toluene phase was measured at $520 \mathrm{~nm}$. Proline concentration was determined against a standard curve ( 0 to $0.5 \mu \mathrm{mol} \mathrm{ml}^{-1}$ ) with L-proline (SigmaAldrich CHEMIE GmbH, Steinheim, Germany).

Pigments were extracted from frozen leaf discs by adding $2 \mathrm{ml}$ of acetone:water $(9: 1, \mathrm{v} / \mathrm{v})$ and grinding with a pestle and mortar. The extract was centrifuged at $10,000 \mathrm{~g}$ for $10 \mathrm{~min}$ at $4{ }^{\circ} \mathrm{C}$ and the supernatant filtered through a $0.2-\mu \mathrm{m}$ filter. Pigments were analyzed by high performance liquid chromatography (HPLC) as described by Wright et al. (1991).

\section{Antioxidant enzymes}

For SOD, GR and CAT, frozen leaves ( $0.5 \mathrm{~g}$ fresh mass) and roots $(0.5 \mathrm{~g}$ fresh mass and diameter $<2 \mathrm{~mm})$ were ground with $2 \%$ polyvinylpolypyrrolidone (PVPP) (Sigma Chemical Co., St. Louis, USA) and sea sand and then homogenized with $5 \mathrm{ml}$ of $100 \mathrm{mM}$ phosphate buffer, $\mathrm{pH} \mathrm{7.8,} \mathrm{containing} \mathrm{2 \%} \mathrm{Tri-}$ ton X-100 (Solon Ind. Pkwy. Solon, Ohio) (Gogorcena et al. 1995). The same extraction medium supplemented with $2 \%$ ascorbic acid (10 mM) was used for APX (Nakano and Asada 1981). The homogenates were centrifuged at $15,000 \mathrm{~g}$ for $20 \mathrm{~min}$ and the supernatants assayed for enzymatic activity. All steps were performed at $4{ }^{\circ} \mathrm{C}$.

Catalase (EC 1.11.1.6) activity was determined by $\mathrm{H}_{2} \mathrm{O}_{2}$ consumption measured as the decrease in absorbance at 240 $\mathrm{nm}$, according to the method of Aebi (1983). The assay medium contained $50 \mathrm{mM} \mathrm{KH} \mathrm{KO}_{4} / \mathrm{K}_{2} \mathrm{HPO}_{4}(\mathrm{pH} 7.0), 40 \mathrm{mM}$ $\mathrm{H}_{2} \mathrm{O}_{2}$ and $100 \mu \mathrm{m}$ extract. Catalase activity was calculated based on an extinction coefficient of $3.94 \mathrm{mM}^{-1} \mathrm{~cm}^{-1}$. Controls lacking either extract or $\mathrm{H}_{2} \mathrm{O}_{2}$ showed no changes in absorbance.

Glutathione reductase (EC 1.6.4.2) was measured by following the oxidation of NADPH at $340 \mathrm{~nm}$ by a modification of the method of Foyer and Halliwell (1976). The assay medium contained $500 \mathrm{mM}$ HEPES (Sigma Chemical) (pH 8.0), 0.25 mM EDTA (Sigma Chemical), 2 mM NADPH (Sigma Chemical), $20 \mathrm{mM}$ oxidized glutathion (GSSG) and $100 \mu \mathrm{l} \mathrm{ex-}$ tract. Control rates were obtained in the absence of GSSG or NADPH. Glutathione reductase activity was calculated based on an extinction coefficient of $6.22 \mathrm{mM}^{-1} \mathrm{~cm}^{-1}$.

Ascorbate peroxidase (EC 1.11.1.11) was measured by a modification of the method of Nakano and Asada (1981). The

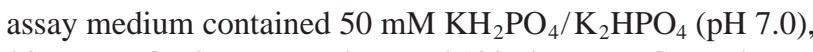
$20 \mathrm{mM} \mathrm{H}_{2} \mathrm{O}_{2}, 8 \mathrm{mM}$ ascorbate and $100 \mu \mathrm{l}$ extract. Control rates were obtained in the absence of extract, ascorbate, or $\mathrm{H}_{2} \mathrm{O}_{2}$. Ascorbate peroxidase activity was calculated based on an extinction coefficient of $2.8 \mathrm{mM}^{-1} \mathrm{~cm}^{-1}$ for ascorbate at $290 \mathrm{~nm}$.

Total superoxide dismutase (EC 1.15.1.1) activity was determined by the inhibition of the formation of epinephrine at $\mathrm{pH} 10.4$ and $30{ }^{\circ} \mathrm{C}$ (Kroniger et al. 1995). The assay medium contained $62.5 \mathrm{mM} \mathrm{Na}_{2} \mathrm{CO}_{3}$ (pH 10.4), $0.125 \mathrm{mM}$ EDTA, 20 $\mathrm{mM} \mathrm{KH}{ }_{2} \mathrm{PO}_{4} / \mathrm{K}_{2} \mathrm{HPO}_{4}$ (pH 7.8), $20 \mathrm{mM}$ epinephrine and 100 $\mu \mathrm{l}$ extract. Control rates were obtained in the absence of extract. One unit of superoxide dismutase activity was defined as the amount of enzyme that inhibited epinephrine formation by $50 \%$.

Standard enzymatic assays were performed in a total volume of $1 \mathrm{ml}$ at $25^{\circ} \mathrm{C}$. A commercial Bio-Rad protein assay (Bio-Rad Laboratories GmbH, Munich, Germany) was used to measure soluble protein concentration by the Bradford method (Bradford 1976).

\section{Statistical analysis}

Data were subjected to two-way analysis of variance (ANOVA) to assess the effects and interactions of treatment and clones, using STATISTICA data analysis software (Version 6 , StatSoft, Tulsa, OK). Values presented are means \pm SE. All statistically significant differences were tested at the $P<0.05$ level.

\section{Results}

\section{Leaf water potential and growth response}

The $\Psi_{\text {pd }}$ of well-watered plants of both clones was maintained at about $-0.30 \mathrm{MPa}$ throughout the experiment (Table 1), whereas $\Psi_{\text {pd }}$ of water-stressed ST51 and CN5 plants declined to $-2.43 \pm 0.27$ and $-1.71 \pm 0.06 \mathrm{MPa}$, respectively, by the end of the experiment (cf. Costa e Silva et al. 2004). Midday leaf water potential did not vary significantly in well-watered plants, whereas it declined to $-3.26 \pm 0.26$ and $-2.46 \pm$ $0.05 \mathrm{MPa}$ in water-stressed ST51 and CN5 plants, respectively, by the end of the experiment. There were significant differences not only between watering regimes $(P<0.001)$, but also between clones $(P<0.05)$ (Table 2$)$, with Clone CN5 maintaining a higher leaf water status than Clone ST51 in the water-stress treatment.

The water-stress treatment significantly reduced growth in terms of total biomass $(P<0.001)$, leaf area $(P<0.001)$, root length $(P<0.05)$ and leaf-to-root-area ratio $(P<0.01)$ (Figure 1 and Table 2). In addition to differences in responses to water availability, the clones differed in leaf area, with Clone ST51 having higher values under well-watered conditions than Clone CN5 $(P<0.01)$. Relative to control values, the water-stress treatment caused a greater decrease in growth (particularly root length) in ST51 plants than in CN5 plants (Figure 1). 
Table 1. Predawn and midday leaf water potentials (MPa) in Eucalyptus globulus Clones ST51 and CN5 subjected to water deficit. Measurements were made throughout the 7-week experiment in well-watered (WW) and water-stressed (WS) plants. Values are means $\pm \operatorname{SE}(n=5)$.

\begin{tabular}{llllll}
\hline Leaf water potential & Week & ST51 WW & ST51 WS & CN5 WW & CN5 WS \\
\hline Predawn & 1 & $-0.35 \pm 0.04$ & $-0.35 \pm 0.04$ & $-0.28 \pm 0.03$ & $-0.28 \pm 0.03$ \\
& 3 & $-0.34 \pm 0.02$ & $-0.89 \pm 0.19$ & $-0.33 \pm 0.01$ & $-0.53 \pm 0.08$ \\
& 5 & $-0.29 \pm 0.02$ & $-1.28 \pm 0.21$ & $-0.28 \pm 0.02$ & $-0.83 \pm 0.07$ \\
Midday & 7 & $-0.27 \pm 0.01$ & $-2.43 \pm 0.27$ & $-0.25 \pm 0.02$ & $-1.71 \pm 0.06$ \\
& 1 & $-1.24 \pm 0.06$ & $-1.24 \pm 0.06$ & $-1.37 \pm 0.04$ & $-1.37 \pm 0.04$ \\
& 3 & $-0.64 \pm 0.05$ & $-1.66 \pm 0.26$ & $-0.63 \pm 0.04$ & $-1.11 \pm 0.05$ \\
& 5 & $-0.68 \pm 0.04$ & $-1.87 \pm 0.22$ & $-0.60 \pm 0.04$ & $-1.37 \pm 0.05$ \\
& 7 & $-0.68 \pm 0.06$ & $-3.26 \pm 0.26$ & $-0.78 \pm 0.04$ & $-2.46 \pm 0.05$ \\
\hline
\end{tabular}

\section{Osmotic potential}

Well-watered plants of ST51 and CN5 had leaf $\Psi_{\pi}$ of $-1.14 \pm$ $0.03 \mathrm{MPa}$ and $-1.19 \pm 0.05 \mathrm{MPa}$, respectively (Table 3). By the end of the experiment, $\Psi_{\pi}$ had declined by $43 \%$ in waterstressed ST51 leaves and 75\% in water-stressed CN5 leaves with significant differences between watering treatments $(P<$ 0.001). In roots, drought stress caused a significant $(P<0.001)$ and larger reduction in $\Psi_{\pi}$ than in leaves. By the end of the experiment, $\Psi_{\pi}$ had declined by $92 \%$ in water-stressed ST51 roots and $87 \%$ in water-stressed CN5 roots with no significant differences between clones.

\section{Carbohydrates and soluble protein concentration}

There were no statistically significant differences between clones or watering regimes in leaf soluble sugar concentration (Tables 2 and 4). By contrast, there was a significant $(P<0.05)$ increase in soluble sugar concentration in roots of water- stressed plants and the increase was higher in ST51 plants than in CN5 plants (55 versus $21 \%$ ).

There were no significant differences in leaf insoluble sugar concentrations between watering regimes or between clones (Tables 2 and 4). However, water stress led to a significant $(P<$ $0.05)$ increase in insoluble sugar concentrations in roots, with ST51 plants showing a slightly higher increase than CN5 plants (49 versus 39\%) (Tables 4 and 5).

In leaves of well-watered plants, soluble sugars accounted for $40 \%$ of the osmotic potential in ST51 and 37\% in CN5, and the corresponding values in water-stressed plants were 51 and $28 \%$. In roots of well-watered plants, soluble sugars accounted for $25 \%$ of the osmotic potential in ST51 and 24\% in CN5, whereas in roots of water-stressed plants the corresponding values were 41 and $33 \%$.

There were no significant differences in leaf or root soluble protein concentrations between treatments or clones (Tables 2 and 5).

Table 2. Statistical significance of the effects of watering regime (W), clone (C) and their interaction as determined by 2-way analysis of variance of leaf variables: leaf water potential (predawn, $\Psi_{\mathrm{pd}}$ and midday, $\Psi_{\mathrm{md}}$ ), leaf area, leaf area/root area, soluble and insoluble sugar concentrations, protein, proline, osmotic potential at full turgor, violaxanthin + antheraxanthin + zeaxanthin (VAZ), lutein, total chlorophyll, glutathione reductase, ascorbate peroxidase and catalase in two Eucalyptus globulus clones. Symbols: ${ }^{*}, * *$ and $* * *$ represent statistical significance at $P<$ $0.05,0.01$ and 0.001 , respectively; and ns $=$ not significant at $P=0.05$.

\begin{tabular}{llll}
\hline Leaf parameters & Watering regime & Clone & W $\times$ C \\
\hline$\Psi_{\text {pd }}$ & $* * *$ & $*$ & $*$ \\
$\Psi_{\text {md }}$ & $* * *$ & $*$ & $\mathrm{~ns}$ \\
Total biomass & $* * *$ & $* *$ & $\mathrm{~ns}$ \\
Leaf area & $* * *$ & $\mathrm{~ns}$ & $\mathrm{~ns}$ \\
Leaf area/root area & $* *$ & $\mathrm{~ns}$ & $\mathrm{~ns}$ \\
Soluble sugars & $\mathrm{ns}$ & $\mathrm{ns}$ & $\mathrm{ns}$ \\
Insoluble sugars & $\mathrm{ns}$ & $\mathrm{ns}$ & $\mathrm{ns}$ \\
Protein & $\mathrm{ns}$ & $\mathrm{ns}$ & $* *$ \\
Proline & $* * *$ & $\mathrm{~ns}$ & $\mathrm{~ns}$ \\
Osmotic potential & $* * *$ & $\mathrm{~ns}$ & $\mathrm{~ns}$ \\
VAZ & $*$ & $* *$ & $\mathrm{~ns}$ \\
Lutein & $*$ & $\mathrm{~ns}$ & $*$ \\
$\beta$-Carotene & $* * *$ & $\mathrm{~ns}$ & $\mathrm{~ns}$ \\
Total chlorophyll & $\mathrm{ns}$ & $\mathrm{ns}$ & $*$ \\
Glutathione reductase & $* * *$ & $\mathrm{~ns}$ & $\mathrm{~ns}$ \\
Ascorbate peroxidase & $* *$ & & \\
Catalase & $\mathrm{ns}$ & & \\
\hline
\end{tabular}




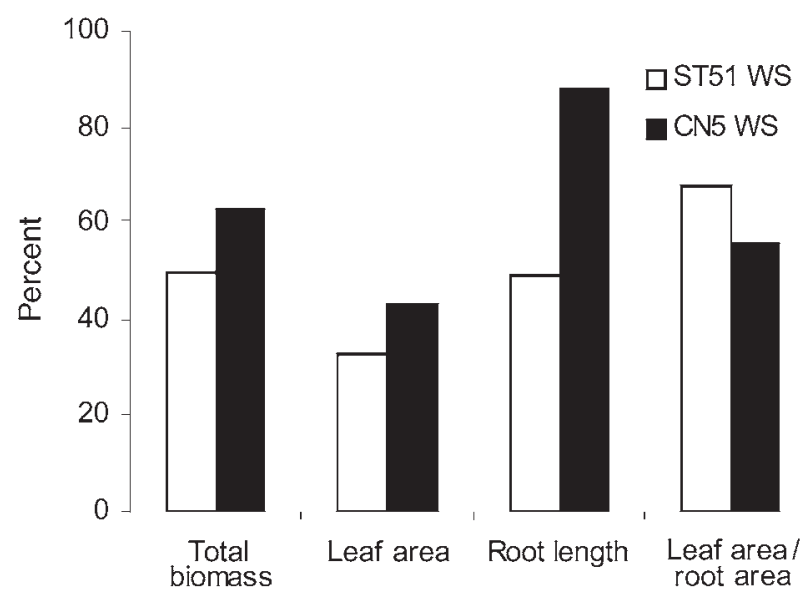

Figure 1. Morphological characteristics of Eucalyptus globulus Clones ST51 and CN5 subjected to water deficit: total biomass (g), leaf area $\left(\mathrm{cm}^{2}\right)$, root length $(\mathrm{m})$ and leaf-to-root area ratio $\left(\mathrm{cm}^{2}\right.$ leaf area $\mathrm{cm}^{-2}$ root area). Measurements were made at the end of the 7-week experiment and are presented as a percentage of the value of well-watered plants. Abbreviation: WS = water-stressed.

\section{Proline concentration}

The water-stress treatment caused a significant increase $(P<$ 0.001) in leaf proline concentration in ST51 plants but not in CN5 plants (Figure 2A). In roots, water stress led to a signifi-
Table 3. Osmotic potential (MPa) of leaves and roots of Eucalyptus globulus Clones ST51 and CN5 subjected to water deficit. Measurements were made at the end of the 7-week experiment in well-watered $(\mathrm{WW})$ and water-stressed (WS) plants . Values are means \pm SE $(n=5)$.

\begin{tabular}{lll}
\hline Treatment & \multicolumn{2}{l}{ Osmotic potential } \\
\cline { 2 - 3 } & Leaves & Roots \\
\hline ST51 WW & $-1.14 \pm 0.03$ & $-0.36 \pm 0.04$ \\
ST51 WS & $-1.63 \pm 0.41$ & $-0.69 \pm 0.10$ \\
CN5 WW & $-1.19 \pm 0.05$ & $-0.37 \pm 0.04$ \\
CN5 WS & $-2.08 \pm 0.12$ & $-0.69 \pm 0.11$ \\
\hline
\end{tabular}

cant increase $(P<0.001)$ in proline concentration in both clones (Figure 2B), and the increase was greater in CN5 roots than in ST51 roots (253 versus 194\%).

In leaves of well-watered plants of both clones, the contribution of proline to the osmotic potential was $0.97 \%$ (on average) compared with $1.16 \%$ (on average) in leaves of water-stressed plants. In roots of both clones, the contribution of proline to osmotic potential was 0.12 and $0.43 \%$ (on average) in wellwatered and water-stressed plants, respectively.

\section{Leaf pigments}

In both clones, violaxanthin + antheraxanthin + zeaxanthin (VAZ) and lutein concentrations were significantly higher $(P<$ $0.05)$ in water-stressed plants than in well-watered plants (Fig-

Table 4. Soluble and insoluble sugar concentrations in leaves and roots of Eucalyptus globulus Clones ST51 and CN5 subjected to water deficit. Measurements were made at the end of the 7-week in well-watered (WW) and water-stressed (WS) plants. Values are means \pm SE $(n=5)$.

\begin{tabular}{lllll}
\hline Treatment & \multicolumn{2}{l}{ Leaf sugars $\left(\mu \mathrm{mol} \mathrm{g} \mathrm{g}^{-1}\right.$ dry mass $)$} & & \multicolumn{2}{l}{ Root sugars $\left(\mu \mathrm{mol} \mathrm{g} \mathrm{g}^{-1} \mathrm{dry} \mathrm{mass}\right)$} \\
\cline { 2 - 4 } & Soluble & Insoluble & Soluble & Insoluble \\
\hline ST51 WW & $460 \pm 50$ & $200 \pm 30$ & $310 \pm 60$ & $200 \pm 30$ \\
ST51 WS & $520 \pm 90$ & $190 \pm 30$ & $480 \pm 40$ & $290 \pm 20$ \\
CN5 WW & $400 \pm 70$ & $280 \pm 70$ & $270 \pm 40$ & $180 \pm 30$ \\
CN5 WS & $450 \pm 60$ & $140 \pm 40$ & $320 \pm 40$ & $250 \pm 40$ \\
\hline
\end{tabular}

Table 5. Statistical significance of the effects of watering regime (W), clone (C) and their interaction as determined by 2-way analysis of variance of root variables: root length, soluble and insoluble sugar concentrations, protein and proline content, osmotic potential and activities of glutathione reductase, ascorbate peroxidase, catalase and superoxide reductase in two Eucalyptus globulus clones. Symbols: *, ** and *** represent statistical significance at $P<0.05,0.01$ and 0.001 , respectively; and $\mathrm{ns}=$ not significant at $P=0.05$.

\begin{tabular}{|c|c|c|c|}
\hline Root parameters & Watering regime & Clone & $\mathrm{W} \times \mathrm{C}$ \\
\hline Total root length & $*$ & ns & ns \\
\hline Soluble sugars & $*$ & ns (0.07) & ns \\
\hline Insoluble sugars & $*$ & $\mathrm{~ns}$ & ns \\
\hline Protein & ns & ns & ns \\
\hline Proline & $* * *$ & ns & ns \\
\hline Osmotic potential & $* * *$ & ns & ns \\
\hline Glutathione reductase & $* * *$ & $* * *$ & ns \\
\hline Ascorbate peroxidase & $* * *$ & ns & ns \\
\hline Catalase & ns & ns & ns \\
\hline Superoxide dismutase & $*$ & $*$ & $*$ \\
\hline
\end{tabular}



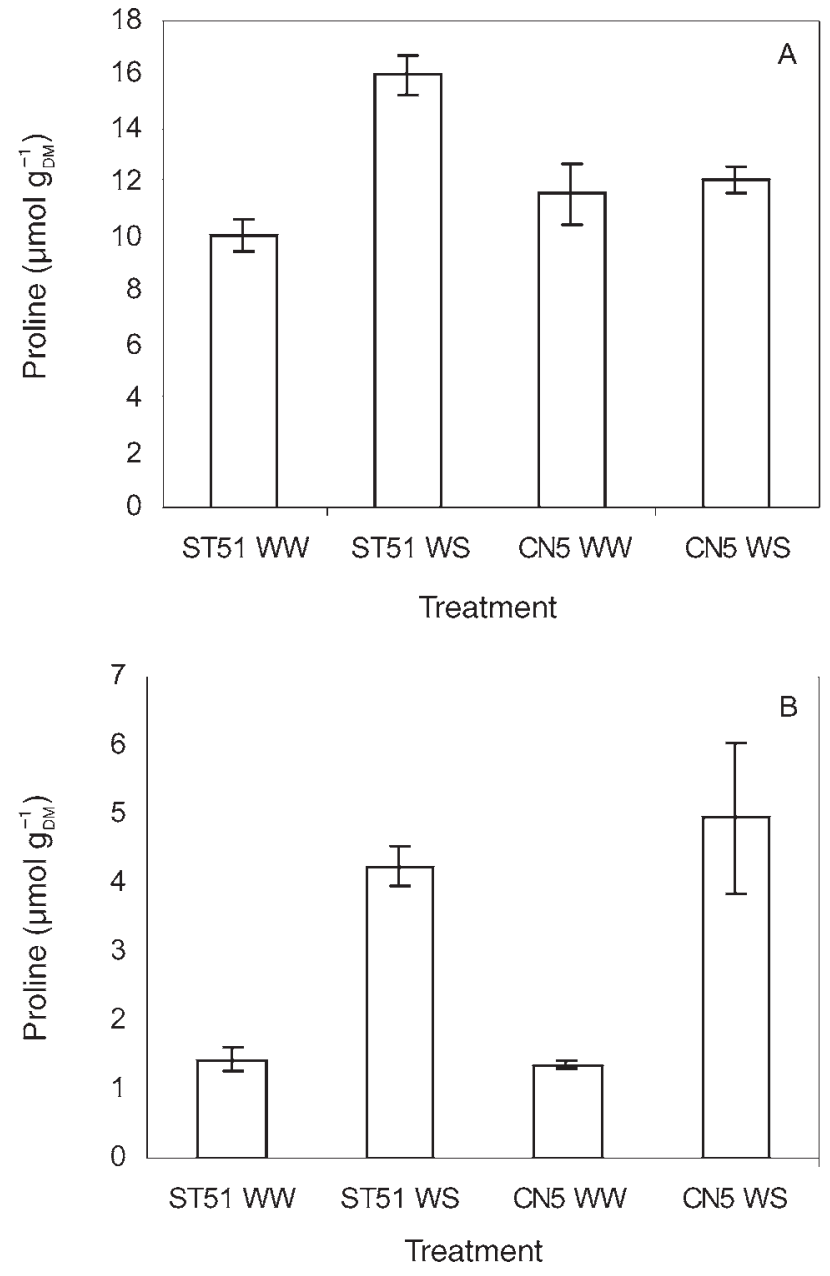

Figure 2. Proline concentrations in leaves (A) and roots (B) of Eucalyptus globulus Clones ST51 and CN5 subjected to water deficit. Measurements were made at the end of the 7-week experiment in well-watered (WW) and water-stressed (WS) plants. Values are means $\pm \operatorname{SE}(n=5)$. Abbreviation: $\mathrm{DM}=$ dry mass.

ure 3). Water stress caused opposite effects on the $\beta$-carotene concentrations of the clones (Figure 3C). The significant clone $\times$ treatment interaction $(P<0.05)$ resulted from a $226 \%$ increase in $\beta$-carotene concentration in ST51plants and a 56\% decrease in CN5 plants. There were no significant treatment or clonal differences in total chlorophyll concentration (Figure 3D).

\section{Antioxidant enzymes}

The effects of water stress on antioxidant enzymatic activities in leaves of the clones were variable (Figure 4). Leaf GR activity in both clones was significantly $(P<0.001)$ decreased by water stress, but particularly in Clone CN5, resulting in a significant clone $\times$ treatment interaction. The water-stress treatment also decreased APX activity, but only in CN5 plants (Figure $4 \mathrm{~A}$ and $4 \mathrm{~B}$ ), again leading to a significant clone $\times$ treatment interaction (Table 2). There were no significant dif- ferences in leaf CAT activity between treatments or clones (Figure 4C).

In roots, the effects of water stress on antioxidant enzymatic activities were more marked than in leaves (Figure 5). In both clones, GR activity was observed only in water-stressed plants and it was significantly $(P<0.001)$ higher in ST51 plants than in CN5 plants (Figure 5A). The activity of APX in roots increased significantly $(P<0.001)$ in both ST51 and CN5 clones in response to water stress $(332 \%$ and $613 \%$, respectively), but there were no statistically significant differences between clones (Figure 5B). There was no significant effect of water stress $(P=0.09)$ or clone on root CAT activity (Figure $5 \mathrm{C})$. The activity of SOD in roots remained stable in CN5 plants and declined in ST51 plants under water stress. There was a significant interaction $(P<0.05)$ between treatment and clone.

\section{Discussion}

We examined several biochemical and physiological responses to water deficit in leaves and roots of E. globulus clones, reported to differ in drought sensitivity (Costa e Silva et al. 2004). We confirmed that Clone CN5 maintained higher leaf water status (higher $\Psi_{\mathrm{pd}}$ and $\Psi_{\mathrm{md}}$ ) and sustained a higher growth rate than Clone ST51 as a result of drought avoidance mechanisms (Costa e Silva et al. 2004). A slowly imposed water deficit resulted in a reduction in total biomass in both E. globulus clones, and the general decline in growth was accompanied by a reduction in the leaf area/root area ratio. Although the drought-induced reductions in total biomass and leaf area did not differ between clones, total root length of Clone CN5 was significantly higher than that of Clone ST51 in the water-stress treatment. A reduction in shoot/root ratio, attributable mainly to a reduction in shoot growth, has been associated with tolerance to limited water availability (Pereira and Chaves 1993).

Both clones responded to water stress by altering osmotic potential, osmoprotectants (sugars and proline), antioxidant activity and pigment composition. In general, osmolyte accumulation in plant cells results in a decrease in cell osmotic potential and thus improves water absorption and cell turgor pressure, which might help sustain physiological processes, such as stomatal opening, photosynthesis and expansion growth under drought conditions (Blum 1996). Furthermore, the accumulation of sugars and proline, mostly in the cytoplasm, can protect cell membranes and proteins and enhance dehydration tolerance (Rathinasabapathi 2000).

In response to the water-stress treatment, there was a small accumulation of soluble sugars in leaves of both clones and a significantly higher accumulation in roots, especially in ST51 plants. The increased accumulation of soluble sugars may reflect osmolyte accumulation as a consequence of water deficits causing a decrease in growth and hence reduced consumption of organic solutes, rather than a physiological mechanism involved in an adaptive plant response (Munns 1988). The difference in growth rates between clones supports this hypothe- 

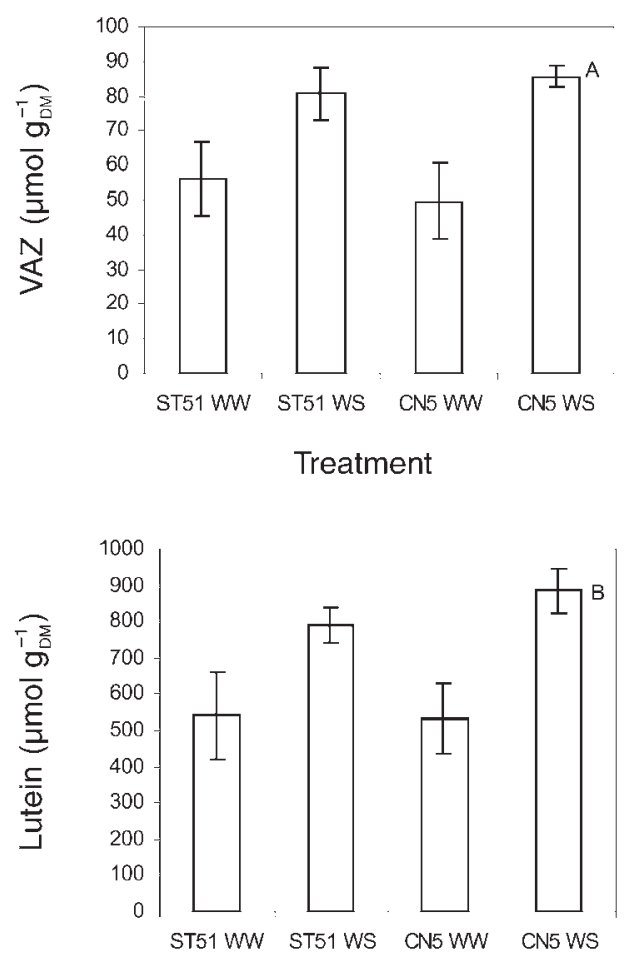

Treatment

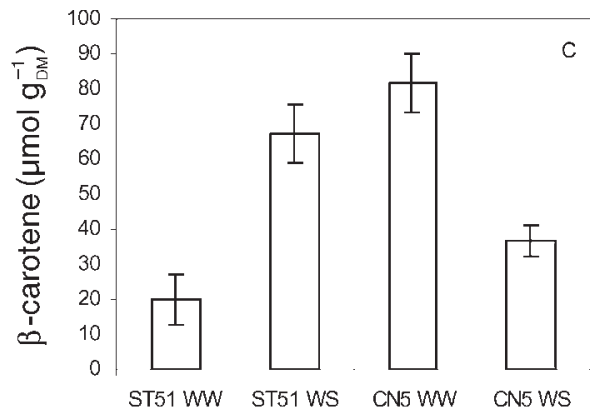

Treatment

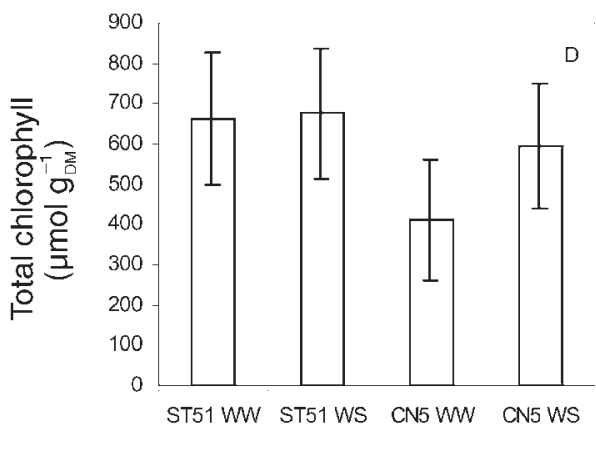

Treatment
Figure 3. Pigment concentrations in leaves of Eucalyptus globulus Clones ST51 and CN5 subjected to water deficit. Measurements were made at the end of the 7-week experiment in well-watered (WW) and water-stressed (WS) plants. (A) VAZ = violaxanthin + antheraxanthin + zeaxanthin, (B) lutein, (C) $\beta$-carotene and (D) total chlorophyll. Values are means \pm $\operatorname{SE}(n=5)$. Abbreviation: $\mathrm{DM}=$ dry mass. sis: roots of ST51 had lower growth rates and higher soluble sugar concentrations than roots of CN5, whereas leaves of both clones ceased growth and showed similar increases in soluble sugar concentrations in response to water stress.

Water stress led to a decline in $\Psi_{\pi}$ in both clones. The contribution of proline to the change in osmotic potential was only about $1 \%$, however, indicating that the drought-induced increase in proline concentration did not significantly contribute to osmotic adjustment in the water-stressed plants. As indicated in other studies, the role of proline in drought-stressed plants may be associated with preservation of enzyme structure and activity (Delauney and Verma 1993, Hare et al. 1999), and with the protection of membranes from damage by ROS produced in response to drought (Hamilton and Heckathorn 2001). However, the greater increase in leaf proline concentration in the drought-sensitive ST51 clone than in the less sensitive $\mathrm{CN} 5$ clone in response to the water-stress treatment cannot be explained on the basis of either a protective or osmotic role. In both treatments, soluble sugars in leaves and roots contributed less to the $\Psi_{\pi}$ in Clone CN5 than in the drought-resistant Clone ST51 (30 versus 50\%), indicating that there is no link between the better performance of CN5 plants and an osmotic role of soluble sugars.

The absence of significant differences in protein concentrations both in leaves and in roots indicates that short-term water stress had little or no effect on the synthesis and hydrolysis of soluble proteins, contrary to previous reports of inhibition of protein synthesis in response to drought (Chaves 1991). On the other hand, the increase in insoluble sugar concentrations in roots of both clones under severe water stress suggests a storage function of these organs in drying soil. In summary, the absence of clonal differences in leaf and root $\Psi_{\pi}$ and osmolytes in the water-stress treatment indicates that differences in drought sensitivity between the clones are not associated with osmotic adjustment in leaves and roots.

Under well-watered growth conditions, the production and destruction of ROS is well-regulated in plant cells. However, under environmental stress, the balance between the production of ROS and the quenching activity of the antioxidant system may be upset (Polle 2001). The capacity of the antioxidative defense system determines whether a cell under stress continues to function or suffers oxidative stress.

Activity of GR in leaves of both clones decreased in response to water stress, particularly in CN5 plants (Figure 4A). Thus, under our experimental conditions, we found no evidence that GR plays a protective role in leaves of waterstressed plants. In contrast, the induction of high GR activity in roots of water-stressed ST51 and CN5 plants (Figure 5A) suggests that GR has a protective function against drought in roots of both clones, perhaps by preventing oxidative stress or slowing the progression of root senescence, or both (Munné- Bosch and Alegre 2004). The large increase in root GR activity in response to drought closely resembled the results obtained by Porcel et al. (2003) for soybean (Glycine $\max (\mathrm{L}$.$) Merr.)$ plants.

The significant treatment $\times$ clone interaction on leaf APX activity suggests that APX has no protective effect against oxidative stress in leaves of the ST51 and CN5 clones. In contrast, 


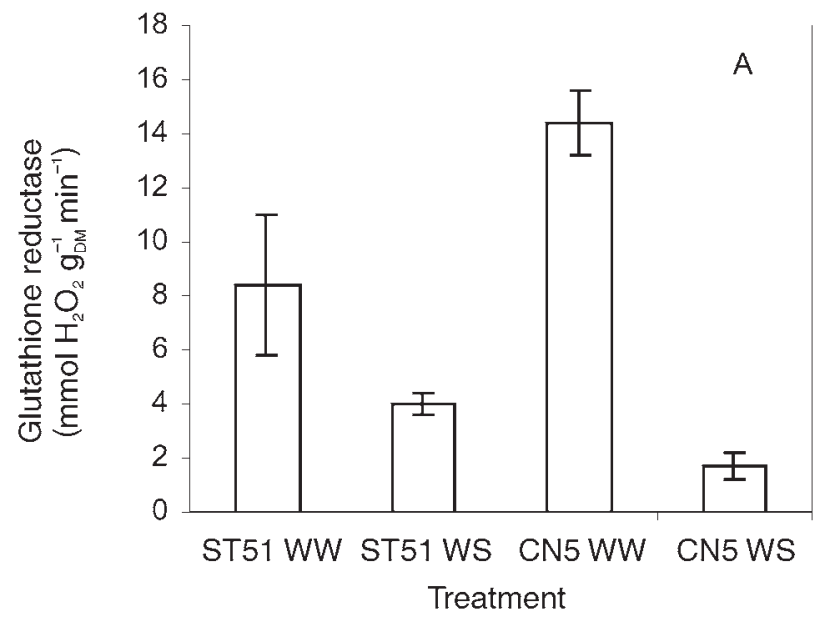

$$
35-
$$$$
30
$$

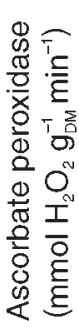

10 $25-$ 20 15 $10-$ $5-$ 0 ST51WW ST51WS CN5WW CN5WS Treatment

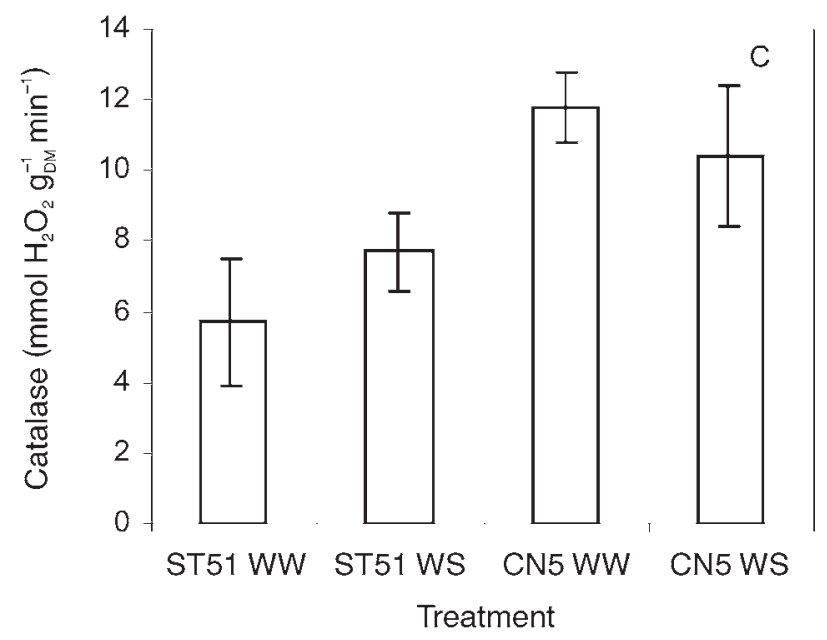

Figure 4. Glutathione reductase (A), ascorbate peroxidase (B) and catalase (C) activities in leaves of Eucalyptus globulus clones ST51 and $\mathrm{CN} 5$ subjected to water deficit. Measurements were made at the end of the 7-week experiment in well-watered (WW) and waterstressed (WS) plants. Values are means $\pm \operatorname{SE}(n=5)$. Abbreviation: $\mathrm{DM}=$ dry mass.

water stress resulted in an increase in root APX activity in both clones, particularly in CN5 plants. Because both GR and APX are key enzymes of the ascorbate-glutathione cycle, we spec- ulate that this cycle provides a mechanism for drought adaptation in Eucalptus roots. Increases in GR and APX activity have also been observed in roots of salt-stressed barley (Hordeum vulgare L.) (Liang et al. 2003), conforming to a commonly observed response to water and salt stress (Munns 2002). Thus, although leaves are highly prone to ROS generation, oxidative stress protection also appears to be critical in plant roots during soil drying.

The lack of statistically significant effects of treatments or clones on CAT activity suggests that this enzyme does not provide protection against drought-induced ROS in leaves or roots of $E$. globulus plants. The only alteration in SOD activity occurred in ST51 roots, where drought led to a decrease in activity. Similarly, decreasing SOD activity has been reported in sunflower in response to salt stress, in cucumber in response to chilling stress and in wheat seedlings in response to water deficit (Lee and Lee 2000, Sgherri et al. 2000, Santos et al. 2001). According to Lee and Lee (2000), the metabolism of ROS is dependent on several functionally interrelated antioxidant enzymes. Chilling stress induced a significant increase in SOD activity in leaves of cucumber only during the first hours of stress imposition and thereafter, SOD activity decreased to control values. A similar transient increase in SOD activity may have occurred in roots of water-stressed CN5 plants. Alternatively, it is possible that the higher basal root SOD activity in CN5 plants than in ST51 plants was sufficient to cope with the drought-induced increase in superoxide production and thereby contribute to the to the higher root growth rate of CN5 plants.

Overall, our results reflect the importance of GR, APX and SOD as a system for scavenging ROS in E. globulus roots. These enzymes appear to be more important than CAT in ROS detoxification in E. globulus.

Leaf concentrations of VAZ and lutein increased in both clones in response to severe water stress, suggesting that carotenoids may be involved in stress protection of leaves, even in plants subjected to moderate irradiance, as was the case in our study. Based on the finding that water stress caused a $226 \%$ increase in $\beta$-carotene in ST51 plants and a $56 \%$ decrease in $\mathrm{CN} 5$ plants, we hypothesize that leaf $\beta$-carotene was more rapidly metabolized in CN5 plants than in ST51 plants, indicating that it served as a protective mechanism in deactivation of ROS (cf. Peñuelas and Munné-Bosch 2005). The concentration of carotenoids did not differ significantly between the clones under severe water stress, suggesting that clonal differences in drought sensitivity are related more to drought avoidance mechanisms than to tolerance of water deficits. In previous work, a comparison of the leaf-level mechanisms for coping with summer stress in central Portugal in four evergreen tree species indicated that E. globulus was able to utilize more light in PSII photochemistry and therefore down-regulation of photosynthesis was less severe than in the evergreen oaks and olive trees (Faria et al. 1998).

In studies of plant responses to drought, it has often been found that one specific mechanism does not confer resistance on its own, but that the interplay of several mechanisms simultaneously is essential (Chaves et al. 2003). We found that both 

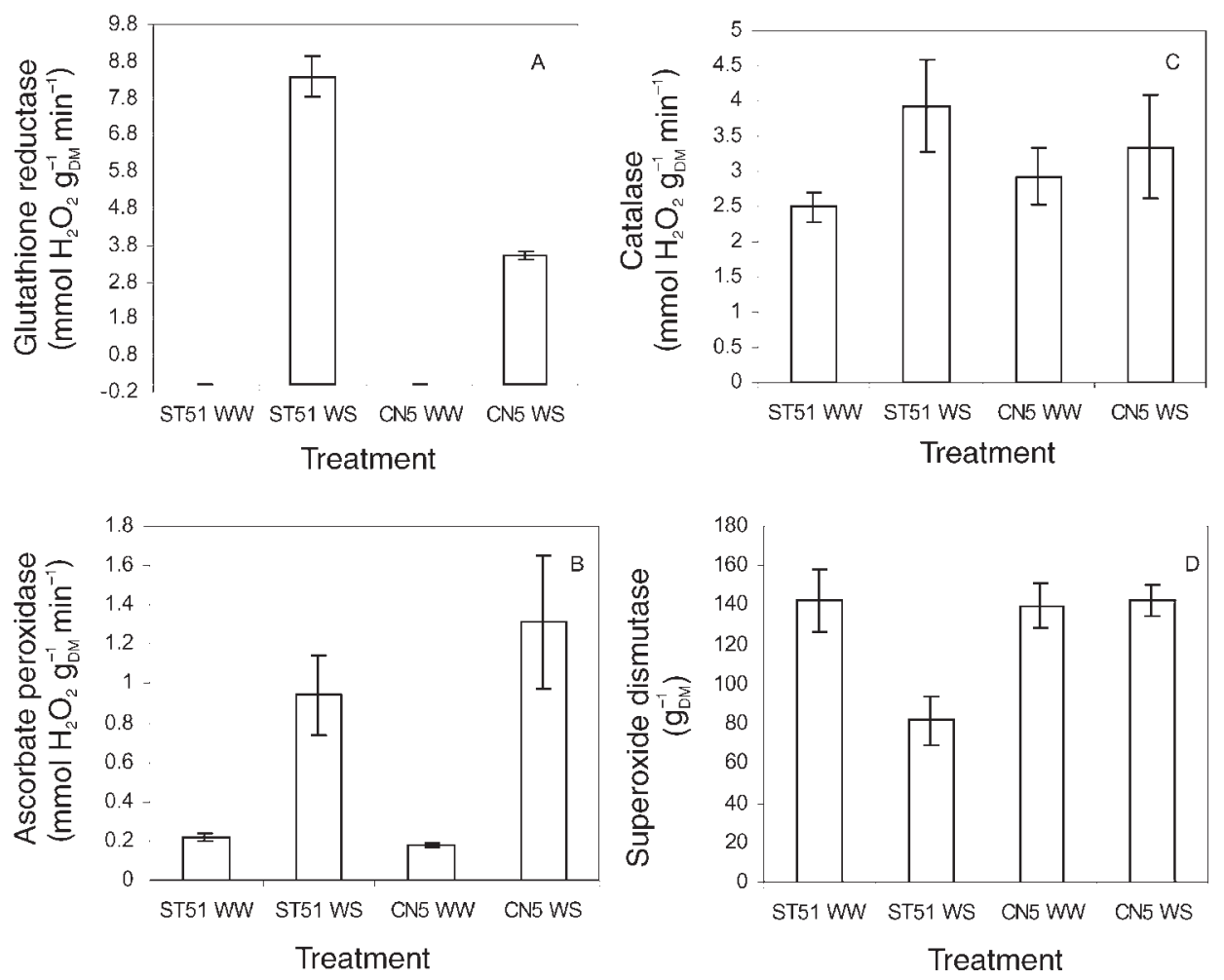

Figure 5. Glutathione reductase (A), ascorbate peroxidase (B), catalase (C) and superoxide dismutase (D) activities in roots of Eucalyptus globulus Clones ST51 and CN5 subjected to water deficit. Measurements were made at the end of the 7-week experiment in well-watered (WW) and water-stressed (WS) plants. Values are means $\pm \mathrm{SE}$ $(n=5)$. Abbreviation: $\mathrm{DM}=$ dry mass.

E. globulus clones had the ability to respond to water deficits at the cellular level by altering both osmotic components and the activity of the antioxidant protection system. Differences in metabolic responses between clones may reflect different degrees of stress experienced during the drought treatment, because the drought-avoiding CN5 plants never reached the same degree of dehydration as the ST51 plants. An important finding of this study was the metabolic response of roots to drought. Although GR activity was not detected in roots of well-watered plants, it increased dramatically in response to water stress, suggesting that GR plays an important role in root responses to drought in E. globulus, possibly preventing fineroot death caused by dehydration.

\section{Acknowledgments}

This research was carried out with financial support from the Commission of the European Communities (Contract No. QLK5-CT2000-01377), Directorate-General Research-Quality of Life and Management of Living Resources Programme. It does not necessarily reflect the Commission's views and in no way anticipates its future policy in this area. A.L. Shvaleva was supported by Fundação para a Ciência e a Tecnologia (FCT, Lisboa) (Grant No. SFRH/BPD/5667/ 2001). The authors thank Viveiros Aliança for providing the plant material.

\section{References}

Aebi, H. 1983. Catalase. In Methods of Enzymatic Analysis. Ed. H. Bergmeyer. Verlag Chemie, Weinheim, 3:273-277.

Bates, L.S., R.P. Waldren and D. Teare. 1973. Rapid determination of free proline for water stress studies. Plant Soil 39:205-207.
Blum, A. 1996. Crop responses to drought and the interpretation of adaptation. Plant Growth Reg. 20:135-148.

Bradford, M.N. 1976. A rapid and sensitive method for the quantification of microgram quantities of protein utilizing the principle of protein-dye binding. Anal. Biochem. 72:248-254.

Chaves, M.M. 1991. Effects of water deficits on carbon assimilation. J. Exp. Bot. 42:1-16.

Chaves, M.M., J.S. Pereira, J.P. Maroco, M.L. Rodrigues, C.P.P Ricardo, M.L. Osorio, I. Carvalh, T. Faria and C. Pinheiro. 2002. How plants cope with water stress in the field. Photosynthesis and growth. Ann. Bot. 89:907-916.

Chaves, M.M., J.P. Maroco and J.S. Pereira. 2003. Understanding plant responses to drought-from genes to the whole plant. Funct. Plant Biol. 30:239-264.

Costa e Silva, F., A.L. Shvaleva, J.P. Maroco, M.H. Almeida, M.M. Chaves and J.S. Pereira. 2004. Responses to water stress in two Eucalyptus globulus clones differing in drought tolerance. Tree Physiol. 24:1165-1172.

Delauney, A.J. and D.P.S. Verma. 1993. Proline biosynthesis and osmoregulation in plants. Plant J. 4:215-223.

Faria, T., D. Wilkins, B. Besford, M. Vaz, J.S. Pereira and M.M. Chaves. 1996. Growth at elevated $\mathrm{CO}_{2}$ leads to down-regulation of photosynthesis and altered response to high temperature in Quercus suber L. seedlings. J. Exp. Bot. 47:1755-1761.

Faria, T., D. Silveri, E. Breia, A. Abadia, J. Abadia, J.S. Pereira and M.M. Chaves. 1998. Differences in the response of carbon assimilation to summer stress (water deficits, high light and temperature) in four Mediterranean tree species. Physiol. Plant. 102: 419-428.

Finkel, T. 1998. Oxygen radicals and signalling. Curr. Opin. Biol. 10: $248-253$.

Foyer, C. and B. Halliwell. 1976. The presence of glutathione and glutathione reductase in chloroplasts: a proposed role in ascorbic acid metabolism. Planta 133:21-25. 
Garcia-Plazaola, J.I., T. Faria, J. Abadia, A. Abadia, M.M. Chaves and J.S. Pereira. 1997. Seasonal changes in xanthophyll composition and photosynthesis of cork oak (Quercus suber L.) leaves under Mediterranean climate. J. Exp. Bot. 48:1667-1674.

Gogorsena, Y., I. Iturbe-Ormaetxe, P.R. Escuredo and M. Becana. 1995. Antioxidant defences against activated oxygen in pea nodules subjected to water stress. Plant Physiol. 108:753-759.

Hamilton, E.W. and S.A. Heckathorn. 2001. Mitochondrial adaptations to $\mathrm{NaCl}$. Complex I is protected by antioxidants and small heat shock proteins, whereas complex II is protected by proline and betaine. Plant Physiol. 126:1266-1274.

Hare, P., W. Cress and J. van Staden. 1999. Proline synthesis and degradation: a model system for elucidating stress-related signal transduction. J. Exp. Bot. 50:413-434.

Kroniger, W., H. Rennenberg, H. Tadros and A. Polle. 1995. Purification and properties of manganese superoxide dismutase from spruce (Picea abies, L. Karst). Plant Cell Physiol. 36:191-196.

Lee, D.H. and C.B. Lee. 2000. Chilling stress-induced changes of antioxidant enzymes in the leaves of cucumber: in gel enzyme activity assays. Plant Sci. 159:78-85.

Liang, Y., Q. Chen, Q. Liu, W. Zhang and R. Ding. 2003. Exogenous silicon $(\mathrm{Si})$ increases antioxidant enzyme activity and reduced lipid peroxidation in roots of salt-stressed barley (Hordeum vulgare L.). J. Plant Physiol. 159:112-121.

Maroco, J.P., J.S. Pereira and M.M. Chaves. 1997. Stomatal responses of leaf-to-air vapor pressure deficit in sahelian species. Aust. J. Plant Physiol. 24:381-387.

Medrano, H., J.M. Escalona, J. Boto, J. Gulias and J. Flexas. 2002. Regulation of photosynthesis of $\mathrm{C}_{3}$ plants in response to progressive drought: stomatal conductance as a reference parameter. Ann. Bot. (Lond.) 89:895-905.

Munné-Bosch, S. and L. Alegre. 2004. Die and let live: leaf senescence contributes to plant survival under drought stress. Funct. Plant Biol. 31:203-216.

Munns, R. 1988. Why measure osmotic adjustment? Aust. J. Plant Physiol. 83:1052-1059.

Munns, R. 2002. Comparative physiology of salt and water stress. Plant Cell Environ. 25:239-250.

Nakagara, S. and S. Sagisaka. 1984. Increases in enzyme activities related to ascorbate metabolism during cold acclimation in poplar twigs. Plant Cell Physiol. 25:822-824.

Nakano, Y. and K. Asada. 1981. Hydrogen peroxide is scavenged by ascorbate-specific peroxidase in spinach chloroplasts. Plant Cell Physiol. 22:867-880.

Osawa, T. and M. Namiki. 1985. Natural antioxidants isolated from Eucalyptus leaf waxes. J. Agric. Food Chem. 33:777-780.

Osawa, T., N. Ramarathnam, S. Kawakishi and M. Namiki. 1992. Antioxidative defense systems generated by phenolic plant constituents. In Phenolic Compounds in Food and their Effects on Health II. Antioxidants and Cancer Prevention. Eds. M.T. Huang, C.T. Ho and C.Y. Lee. ACS Symp. Ser. 507:122-134.
Peñuelas, J. and S. Munné-Bosch. 2005. Isoprenoids: an evolutionary pool for photoprotection. Trends Plant Sci. 10:166-169.

Pereira, J.S. and M.M. Chaves. 1993. Plant water deficits in Mediterranean ecosystems. In Water Deficits: Plant Responses from Cell to Community. Eds J.A.C. Smith and H. Driffiths. BIOS Scientific Publishers, Oxford, pp 235-251.

Polle, A. 2001. Dissecting the superoxide dismutase-ascorbate peroxidase-glutathione pathway in chloroplasts by metabolic modeling. Computer simulations as a step towards flux analysis. Plant Physiol. 126:445-462.

Polle, A. and H. Rennenberg. 1992. Field studies on Norway spruce trees at high altitudes. II. Defense systems against oxidative stress in needles. New Phytol. 121:635-640.

Porcel, R., J.M. Barea and J.M. Ruiz-Lozano. 2003. Antioxidant activities in mycorrhizal soybean plants under drought stress and their relationship to the process of nodule senescence. New Phytol. 157:135-143.

Quick, W.P, M.M. Chaves, R. Wendler et al. 1992. The effect of water stress on photosynthetic carbon metabolism in four species grown under field conditions. Plant Cell Environ. 15:25-35.

Rathinasabapathi, B. 2000. Metabolic engineering for stress tolerance: installing osmoprotectant synthesis pathways. Ann. Bot. (Lond.) 86: 709-716.

Robyt, J. and B. J. White. 1987. Biochemical techniques: theory and practice. Brooks/Cole Pub., Monterey, CA, USA, 407 p.

Rubio, M.C., E.M. Gonzalez, F.R. Minchin, K.J. Webb, C. ArreseIgor, J. Ramos and M. Becana. 2002. Effects of water stress on antioxidant enzymes of leaves and nodules of transgenic alfalfa overexpressing superoxide dismutases. Physiol. Plant. 115: 531-540.

Santos, V.C.L., A. Campos, H. Azevedo and G. Caldeira. 2001. In situ and in vivo senescence induced by $\mathrm{KCl}$ stress: nutritional imbalance, lipid peroxidation and antioxidant metabolism. J. Exp. Bot. 52:351-360.

Sgherri, C.L.M., M. Maffei and F. Navari-Izzo. 2000. Antioxidative enzymes in wheat subjected to increasing water deficit and rewatering. J. Plant Physiol. 157:273-279.

Smirnoff, N. 1998. Plant resistance to environmental stress. Curr. Op. Biotechnol. 9:214-219.

Volaire, F., H. Thomas and F. Lelievre. 1998. Survival and recovery of perennial forage grasses under prolonged Mediterranean drought. I. Growth, death, water relations and solute content in herbage and stubble. New Phytol. 140:439-449.

Wingsle, G. and J.E. Hallgren. 1993. Influence of $\mathrm{SO}_{2}$ and $\mathrm{NO}_{2}$ exposure on glutathione, superoxide dismutase and glutathione reductase activities in Scots pine needles. J. Exp. Bot. 259:463-470.

Wright, S.W., S.W. Jeffrey, R.F.C. Mantoura, C.A. Lewellyn, T. Bjornlund, D. Repeta and N. Welchmeyer. 1991. Improved HPLC method for analysis of chlorophyll and carotenoids in marine phytoplankton. Mar. Ecol. Prog. Ser. 77:193-194. 